\title{
Extracellular matrix grafts: From preparation to application (Review)
}

\author{
YONGSHENG JIANG $^{1 *}$, RUI LI ${ }^{1,2^{*}}$, CHUNCHAN HAN $^{1}$ and LIJIANG HUANG ${ }^{1}$ \\ ${ }^{1}$ Science and Education Management Center, The Affiliated Xiangshan Hospital of Wenzhou Medical University, Ningbo, \\ Zhejiang 315700; ${ }^{2}$ School of Chemistry, Sun Yat-sen University, Guangzhou, Guangdong 510275, P.R. China
}

Received July 30, 2020; Accepted December 3, 2020

DOI: $10.3892 /$ ijmm.2020.4818

\begin{abstract}
Recently, the increasing emergency of traffic accidents and the unsatisfactory outcome of surgical intervention are driving research to seek a novel technology to repair traumatic soft tissue injury. From this perspective, decellularized matrix grafts (ECM-G) including natural ECM materials, and their prepared hydrogels and bioscaffolds, have emerged as possible alternatives for tissue engineering and regenerative medicine. Over the past decades, several physical and chemical decellularization methods have been used extensively to deal with different tissues/organs in an attempt to carefully remove cellular antigens while maintaining the non-immunogenic ECM components. It is anticipated that when the decellularized biomaterials are seeded with cells in vitro or incorporated into irregularly shaped defects in vivo, they can provide the appropriate biomechanical and biochemical conditions for directing cell behavior and tissue remodeling. The aim of this review is to first summarize the characteristics of ECM-G and describe their major decellularization methods from different sources, followed by analysis of how the bioactive factors and undesired residual cellular compositions influence the biologic function and host tissue response following implantation. Lastly, we also provide an overview of the in vivo application of ECM-G in facilitating tissue repair and remodeling.
\end{abstract}

Correspondence to: Dr Rui Li, School of Chemistry, Sun Yat-sen University, 135 Xingang Xi Road, Guangzhou, Guangdong 510275, P.R. China

E-mail: 791853868@qq.com

Dr Lijiang Huang, Science and Education Management Center, The Affiliated Xiangshan Hospital of Wenzhou Medical University, 291 Dandong Street, Ningbo, Zhejiang 315700, P.R. China E-mail: 13777030956@163.com

*Contributed equally

Key words: extracellular matrix grafts, decellularization protocols, tissue engineering, the host response

\section{Contents}

1. Introduction

2. ECM-G characterization

3. Methods of decellularization treatments

4. Removal of residual cellular components and chemicals

5. Application of ECM-P in regenerative medicine

6. Challenges and future outlook on ECM-P

7. Conclusions

\section{Introduction}

The extracellular matrix (ECM) derived from organs/tissues is a complex, highly organized assembly of macromolecules with an adequate three-dimensional (3D) organization (1). Dry ECM powders can be further processed to generate various injectable hydrogels by enzymatical digestion. To match tissue defects and improve therapeutic outcomes, these ECM-hydrogels have been combined with synthetic materials to fabricate electrospun nanofibers or 3D-printed scaffolds/conduits via electrospinning technology or 3D printing. The prepared hydrogels or solid scaffolds can seed with stem cells and/or incorporate with growth factors (GFs) to further enhance their bioactivity and repair function. These extracellular matrices and their final products are all termed as the decellularized matrix grafts (ECM-G) or the ECM preparations (ECM-P). In addition to regulating intracellular signaling pathways for inducing cell adhesion, these biologic ECM-P also provide a permissive environment for cell growth, proliferation, migration and differentiation, which have widely applied for the therapeutic reconstruction in heterologous tissue disorder (2). Commonly, ECM-P consists of a complex mixture of structural and functional proteins, including collagen, fibronectin, laminin, glycosaminoglycans, and growth factors (GFs). Besides abundant bioactive factors, its inherent cross-linked polymeric network and suitable mechanical property, not only provides physical support for tissue integrity and elasticity, but also modulates the wound healing response towards tissue remodeling $(3,4)$. Additionally, ECM-P has been used in various forms, such as scaffold incorporated with stem cells and/or GFs, and even as a bioink for constructing 3D-printed conduits, which have been implanted in virtually every body system (5). 
Injectable materials prepared from untreated raw ECM frequently invoke chronic inflammatory response and host foreign body reaction in a variety of body systems, due to residual immunogenicity components, such as Galactose- $\alpha(1,3)$-galactose ( $\alpha$-gal), major histocompatibility complex class I (MHC I), endotoxins and cell-derived nucleic acids (6). Additionally, some pathogenic contaminations contained in the biological ECM material may also provoke severe immune rejection and foreign body response in preliminary xenografts (7). They are divided into two major categories: Viral particles/elements and salmonella (8). The former is particularly problematic in terms of xenozoonoses, including brucellosis, leptospirosis, and tularellosis. The latter mainly refers to prions, which are derived from xenogeneic and allogeneic tissue sources (9). Thus, the objective on any decellularization process is maximizing the removal of these residual pathogenic contaminants or extracellular antigen molecules, while retaining the functional performance of non-immunogenic ECM and maintaining its native ultrastructure and mechanical strength. Currently, the most commonly utilized methods for decellularization of xenogeneic and allogeneic tissues involve physical, chemical, and enzymatic approaches (10). The choice of these decellularization approaches (single or combined method) depends on the complex intrinsic structure, composition, and mechanical properties of the raw ECM (11). Following the decellularization and solubilization of raw ECM, the resulting ECM-P should still retain the tissue-specific composition and nanostructure that are essential in contributing to ischemic injury repair, tissue regeneration or organ replacement.

The use of ECM grafts (ECM-G) for tissue engineering and drug delivery has already been broadly investigated (3). The ideal ECM-G for regenerative medicine should be clear of cell residues from the tissue source, and comprises a loosely organized nanofibrous architecture with interconnecting pores, which are essential for nutrient and gas exchange for healthy cell migration and growth (12). In addition to having biocompatible, biodegradable, and adequate biomechanical properties, the ECM-G should also display appropriate viscoelasticity and match the permeability property of the autologous homologous tissue (13). Moreover, the proteolytic turnover of grafted ECM should match the rate of new tissue formation in order to withstand mechanical stress from neighboring tissues during the regeneration period $(14,15)$. Furthermore, ECM-G has been developed as a delivery vehicle for incorporating GFs and/or cells to enhance the repair and regeneration of the damaged tissues and holds promising potential for improving the therapy of traumatic diseases.

In this review, we firstly provide an overview of the unique properties of ECM-G and different decellularization methods for achieving sufficient cell removal from source tissues. Then, we discuss the effect of undesired residual cellular material invoking the degree of immune response. Finally, applying ECM-G for tissue engineering and regenerative medicine will be discussed, including current limitations and future directions (Fig. 1).

\section{ECM-G characterization}

ECM-G is a class of naturally derived proteinaceous biomaterials, with excellent biophysical, biomechanical, and biochemical properties, which can provide biological signals and maintain tissue microarchitecture for guiding on cell growth, differentiation, neovascularization and functional improvement (16). It has been shown that collagen and elastin, both of which are the most abundant proteins in the ECM-G, played a critical role in controlling tissue osmotic pressure and regulating intracellular signaling cascades that direct stem cell differentiation and function $(17,18)$. Glycosaminoglycans (GAGs) are also regarded as important associated macromolecules found in the ECM-G, as they generally served as crosslinkers for carrying GFs because their binding sites are highly negatively charge, leading to high affinity to cationic GFs (19). Thus, ECM-G also serve as a drug delivery vehicle for the controlled release of GFs in a spatial and temporal manner when applied in pre-clinical research. Moreover, their thermo-responsive feature is suitable for injecting a cavity site of damage via a catheter or syringe. In addition, the three-dimensional cross-linked network of fibers is another feature that renders them capable of holding large amounts of water. Although the pore size, fiber diameter and fiber alignment of ECM-G vary from different source tissue, its typical nano-scale topography is enough to be sensed and manipulated by infiltrating cells (20). The viscoelastic property of ECM-G is another important parameter for evaluating stiffness and solid-like behavior, which can be accurately determined by turbidimetric gelation kinetics and rheology. A suitable viscosity of the pre-gel solution is favorable for supporting stem cell differentiation and proliferation for in vitro culture and promoting the constructive and functional outcome of tissues and organs. For example, the 3D meniscus-derived hydrogel with storage modulus (a typical index for reflecting viscosity) of $838 \pm 296 \mathrm{~Pa}(12 \mathrm{mg} / \mathrm{ml})$ showed good cellular compatibility by facilitating the differentiation of bone marrow mesenchymal stem cells into nucleus pulposus-like cells after culturing for 2 weeks (21). In vivo examination of a low viscosity ECM hydrogel derived from porcine spinal cord showed that it remained within the defect site at body temperature $\left(37^{\circ} \mathrm{C}\right)$ condition which stimulates neovascularization and axonal outgrowth into the cavity site of the acute model of spinal cord injury (SCI) (22).

The different matrix density of various hydrogels, including water content and macromolecular density, is mainly dependent on tissue sources and status (23). Generally, hydrogel composition and density play important roles in regulating cell activity and phenotype (24). The abundant water content filling the space between hydrogel crosslinks allows for the diffusion of solute molecules. Bio-activate molecules, such as GFs, proteoglycans and collagens, are necessary for the activation of intracellular signaling cascades through integrin receptors to induced cell adhesion, migration, proliferation and differentiation (1). Thus, an ideal natural hydrogel should retain several distinct ECM macromoleculars as much as possible and contain water with proper proportion in case of reduced mechanical force and viscoelastic property for the prepared hydrogel products. Preclinical rodent studies using porcine-derived urinary bladder matrix (UBM)-ECM hydrogel with the concentration of $8 \mathrm{mg} / \mathrm{ml}$ implanted into a 14-day-old stroke cavity induced a robust invasion of endothelial cells with neovascularization for brain regeneration (25). Further research will focus on optimizing the matrix density 


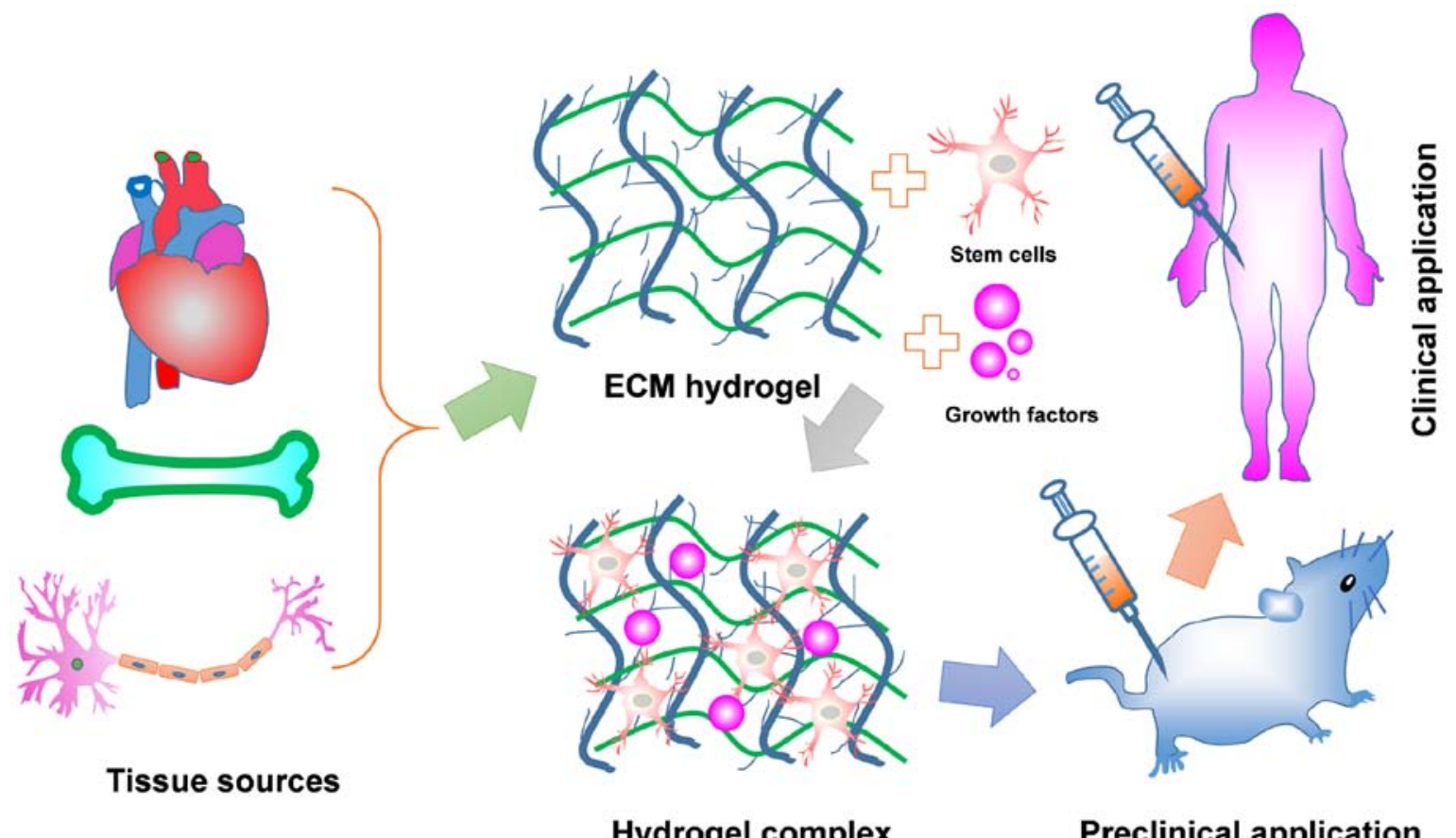

Figure 1. Schematic representation of ECM hydrogel from preparation to application. The native tissues can achieve a diversity of ECM hydrogels via combination of physical, chemical and biological approaches together. The prepared ECM hydrogels themselves with/without incorporating growth factors and/or stem cells are used for tissue repair and regeneration, including spinal cord injury, peripheral nerve injury and myocardial infarction. Some of these may become a primary option for remodeling a variety of clinical tissues defects.

of various hydrogels to open new therapeutic avenues for tissue engineering and regenerative medicine.

Overall, these topological, biochemical and mechanical properties of the ECM-G are essential for modulating diverse fundamental aspects of cell biology and functional outcomes in disease models. Generally, the intrinsic property of a specific ECM-G is mostly determined by the source of tissue type and species. However, the optimal decellularization method is critical for the resulting ECM quality concerning ultrastructure and molecular composition (26). Thus, successful procedures for ECM preparations must relate to the tissue of origin, comprehensively utilizing physical, chemical and biological methods to remove cellular material as much as possible, while retaining the ECM biopolymer components.

There are extensive molecular changes occurring in the ECM including post-translational modification (e.g., glycosylation), proteolytic processing, crosslinking, assembling into polymers and higher complex structures. All these processes are crucial for ECM properties and function, turnover and stability, as well as cellular interactions. These modifications solve the specific issue of different diseases. For instance, it has been shown that ECM proteins, such as collagen, contained in the subendothelial basement membrane could activate platelets, leading to thrombosis at the site of anastomosis during vascular surgery (27). To overcome this shortcoming, chemically modified vascular ECM was developed via covalently immobilizing anticoagulant heparin onto the ECM using collagen binding peptide (CBP) as an intermediate linker that selectively binds collagen within ECM. This heparin-modified ECM exhibits beneficial effects on reducing long-term thromboresistance and targeting VEGF to facilitate the adhesion and growth of endothelial cells (28). Another representative study by Li et al identified nanofiber-hydrogel modification for repairing SCI (29). They engineered an injectable nanofiber-hydrogel composite (NHC) by covalently conjugating hyaluronic acid (HA) hydrogel with electrospun polycaprolactone (PCL) fibers. This unique bonding resulted in a structure that possessed mechanical strength and porosity to prevent contused spinal cord collapse and induce cellular migration within the injury site. After injecting this NHC into the cavity region of an adult rat with spinal cord contusion, macrophage polarization, vascularization, neurogenesis and axonal growth became significantly ameliorated at 28 days treatment.

\section{Methods of decellularization treatments}

Decellularization has become a popular technique for transforming different organs, such as the skin, heart, liver, kidneys, muscle, sis mucosa, nerves, tendons, ligaments and blood vessel, into bioactive ECM-G through physical and/or chemical processing (30). Since different organs or tissues have their unique compositions and mechanical behavior which are closely associated with regulating cell behavior and tissue regeneration, these unique compositions and inherent property must be retained as much as possible during decellularization to obtain the biologic ECM-G (10). Several popular methods have been examined for performing decellularization, which can be mainly classified as physical, chemical and biological approaches (31). These decellularization methods require various decellularization agents that involve specific purpose, extent, influence factor and effect on ECM (Table I). A complete decellularization process should combine these approaches together, that is, firstly destroying 
Table I. Selected agents and techniques for decellularizing tissue.

Methods/Refs. $\quad$ Characteristics $\quad$ Effects on ECM

Snap freezing

$(103-105)$

\section{Mechanical}

sonication $(106,107)$

Mechanical agitation

$(44,108)$

Triton X-100

(109-111)

SDS $(45,112,113)$

Sodium deoxycholate

(114-116)

CHAPS $(44,117)$

Trypsin $(47,48)$

Pepsin $(118,119)$

Lipase $(120,121)$

Collagenases (123)

Nucleases $(123,124)$
Decellularization of tendinous, ligamentous tissue and nerve tissue

Usually combined with complement chemical and enzymatic techniques

Affected by temperature

Tissues with hard structures

Usually combined with complement chemical and enzymatic techniques

Affected by mechanical frequency and amplitude

Removal of cellular contents

Usually combined with complement chemical and enzymatic techniques

Affected by the speed and length of mechanical agitation

Removing nuclear and cytoplasmic waste

Mixed results with efficacy

Dependent on tissue

Affected by exposure time, temperature, and concentration

Applying for retaining the overall matrix structure

Very effective for removal of cellular components

from tissue

Affected by exposure time, temperature, and concentration

Very effective for removing cellular remnants

Causing disruption to the native tissue architecture

Affected by exposure time, $\mathrm{PH}$ and concentration

Cell removal from thinner tissues, such as blood

vessels and lung

95\% removal efficiency of nuclear materials

Affected by $\mathrm{pH}$ and concentration

Specifically target ECM proteins

Strongly damage the ECM proteins collagen laminin, and fibronectin

Affected by exposure time, temperature, $\mathrm{pH}$ and concentration

Generally target ECM proteins

Milld damage the ECM proteins collagen laminin, and fibronectin

Affected by exposure time, temperature, $\mathrm{pH}$ and concentration

Specifically targets lipids

Strongly efficiency

Affected by exposure time, temperature, $\mathrm{pH}$ and concentration

Specifically targets collagen at early step

Strongly efficiency

Affected by exposure time, temperature, $\mathrm{pH}$ and concentration

Specifically break down DNA or RNA sequences

Highly efficiency

Affected by temperature, $\mathrm{pH}$ and concentration
Disruption of cellular membranes and inducing cell lysis

Largely damage the ECM structure

Direct damage to ECM

More effective cell removal from thin tissues

Mild disruption of ultrastructure and removal of GAG

Removes nuclear remnants and

cytoplasmic proteins

Damages the matrix, similar to the SDS

Effectively removes cells in thin tissues and mildly disrupts ultrastructure in thin tissues

Digestion of the proteins in the ECM, in particular collagen laminin, and fibronectin

Damage ECM proteins if digested too long

Hydrolyzing fat to derive adipose derived ECM

Effectively removes collagen in ECM Prolonged expose will disrupt ECM ultrastructure

No function on ECM proteins;

Only removal of nucleotides

SDS, sodium dodecyl sulfate; CHAPS, 3-[(3-cholamidopropyl)dimethylammonio]-1-propanesulfonate; GAGs, glycosaminoglycans. 
the cell membrane via physical shaking or ionic detergents, followed by solubilization of cytoplasmic and nuclear cellular components using sodium dodecyl sulphate (SDS) and sodium deoxycholate, and finally digestion of the extracellular matrix into a homogeneous gel by trypsin, dispase and phospholipase. Furthermore, this effective removal of cellular components is able to achieve further improvement through coupling with mechanical agitation. Nevertheless, it should be highlighted that the entire removal of cytoplasmic and nuclear components while preserving the entire/native extracellular matrix entities and structure is an extremely difficult task. The optimal recipe of decellularization agents is dependent upon different specific tissues, as well as the intended clinical application (32). Several decellularization methods have been developed for a variety of tissues (Table II) and these will be reviewed in the following sections.

Physical methods. A variety of physical methods, such as freezing, mechanical agitation and sonication, have been frequently applied to facilitate tissue decellularization. Snap freezing has been used to disrupt cell-cell and cell-matrix bonds via the formation of intracellular ice crystals (33). After rapidly reducing the temperature of a tissue to the freezing point, cell lysis occurred immediately, facilitating the removal of immunogenic material from the tissue. However, it should be noted that the rate of temperature change for special tissue must be carefully controlled to protect matrix integrity from ice crystals disruption. Similarly, mechanical agitation is another effective method for conducting cell lysis using a magnetic stir plate or an orbital shaker (34). However, for tissue from the small intestine and the urinary bladder, mechanical agitation alone is not sufficient to completely remove intracellular contents and immunogenic macromolecules due to the fragility of the organs and their internal structural complexity. Thus, this technology is only used at the beginning of the decellularization protocol to enhance the efficacy of further efforts to clear cellular debris from the tissue. Sonication is also commonly used to destroy cell membranes to achieve the goal of removing nuclear remnants and cytoplasmic proteins (35). Moreover, the optimal magnitude or frequency of sonication for breaking down cells is dependent on the composition, volume, and density of the tissue. Along with chemical or enzymatic methods, these mechanical methods have been used successfully in assistance of cell lysis and removal of cellular debris.

Chemical methods. Chemical methods involve the use of a variety of detergents to disrupt cell-cell and cell-matrix bonds, which have been regarded as the most extensive and robust method for decellularization $(36,37)$. These detergents can be classified as four categories: Ionic (sodium dodecyl sulfate: SDS), nonionic (Triton X-100), zwitterionic (CHAPS), alkaline and acid. The mechanism of these detergents for decellularization includes facilitating cell lysis and solubilizing the released cellular components through the formation of micelles (38). The choice of decellularized detergents depends on tissue characteristics, such as cellular density, lipid content, and thickness. The following section will summarize the optimal recipe of decellularization agents for removing cellular components efficiently from the entire organ system.
Ionic detergents are subdivided into cationic and anionic solutions. Among them, sodium dodecyl sulfate (SDS) and sodium deoxycholate are representative examples for the removal of cellular debris from tissues (39). SDS is commonly used in the removal of nuclear remnants and cytoplasmic proteins, while sodium deoxycholate proved to be superior for solubilizing cytoplasmic and nuclear membranes. Thus, they are generally combined together to effectively eliminate cellular content in the medullary regions of dense organs, such as the kidney (40). However, there are some limitations when fusing ionic detergents for decellularization, such as the denaturation of ECM proteins and disruption of native tissue structure (41). Conversely, Triton X-100, a nonionic detergent, has the least negative impact on the protein structure and is therefore commonly used for decellularization protocols (42). When Triton X-100 is applied to decellularize a heart valve, a complete removal of nuclear remnants and maintenance of the native ECM structure and composition after $24 \mathrm{~h}$ immersion is observed (43). CHAPS is a zwitterionic detergent that has been confirmed to have a mild ability to retain mechanical strength when used for the decellularization of lungs (44). CHAPS-treated artery tissue is presented as an intact structure with native collagen and elastin morphology and the collagen content is approximately the same as the native artery (45). Acidic and alkaline solutions, including $\mathrm{HCl}$ and $\mathrm{NaOH}$, are commonly used to disrupt cell membranes and solubilize the cytoplasmic component at low concentrations. Moreover, it has also been shown that $\mathrm{pH}$ change in ECM digestible solution to prepare porcine spinal cord tissue via sequentially adding $\mathrm{NaOH}$ and $\mathrm{HCl}$, increased the rate of gelation (46). Regarding the types and concentrations of chemicals employed in the decellularization process, it is generally more advantageous to use different chemicals and form a proper combination to exert the optimum decellularization efficiency.

Enzymatic methods. Enzymatic technology for decellularization is frequently utilized to disrupt the interactions between the cells and the ECM, or to remove antigenic material to decrease immunogenicity (47). Generally, proteases (e.g., trypsin, pepsin), nucleases (e.g., DNase, RNase), lipase, heparinases and hyaluronidase are the most widely applied proteolytic enzymes in decellularization protocols for a variety of tissues. The advantages of using enzymatic treatments for efficient decellularization are listed as follows $(48,49)$ : i) Efficient decellularization via combining with other detergents; ii) maintaining the structural integrity of the ECM for complex organs; iii) targeting specific target molecules removal in tissues, such as Gal epitope and DNA. It has been shown that enzymatic methods for the removal of cell debris are through specifically targeting the proteins to disrupt cell-ECM adhesions. As one of the most commonly used proteolytic enzymes, trypsin inactivates cell surface receptors, apart from adhesion complexes. Moreover, it exerts the maximal enzymatic activity to disrupt cell-matrix interactions in tissues at the condition of $37^{\circ} \mathrm{C}$ and $\mathrm{pH}=8.0$ (50). Although trypsin alone is able to decellularize a soft tissue entirely, efficiency in the removal of complex tissues is shown to be greater when it combines with other detergents, including EDTA, and $\mathrm{NaCl}$ (51). Pepsin in weak acetic acid increases the yield of highly crosslinked fibrillar collagen (e.g., type I from skin, bone or tendon) but decreases 
Table II. Applications of different organ decellularization techniques to various organs.

\begin{tabular}{|c|c|c|c|c|}
\hline Organ & Decellularization agent & Solubilization protocol & Species & (Refs.) \\
\hline Heart & $\begin{array}{l}10 \mathrm{U} / \mathrm{ml} \text { heparinized water } \\
5.0 \% \mathrm{SDS} \\
1 \%(\mathrm{v} / \mathrm{v}) \text { Triton } \mathrm{X}-100\end{array}$ & $\begin{array}{l}\text { 10X PBS } \\
\text { RT, } 48 \mathrm{~h}\end{array}$ & Porcine & (125) \\
\hline Lung & $\begin{array}{l}0.0035 \% \text { Triton-X } 100 \\
0.1 \% \text { SDS } \\
0.1 \% \text { potassium laurate }\end{array}$ & $\begin{array}{l}\text { Perfusion } \\
1.5 \mathrm{mg} / \mathrm{ml} \text { pepsin }\end{array}$ & Rat & (126) \\
\hline Liver & $\begin{array}{l}4 \% \text { Triton } \mathrm{X}-100 \\
10 \mathrm{mM} \text { Tris- } \mathrm{HCl} \\
0.25 \% \text { trypsin }\end{array}$ & $\begin{array}{l}\text { Voytik-Harbin } \\
10 \mathrm{mg} \text { pepsin }\end{array}$ & Rat & (127) \\
\hline Kidney & $\begin{array}{l}\text { Gradient of SDS }(0.5 \%-1.0 \%) \\
0.1 \% \text { Triton X-100 }\end{array}$ & $\begin{array}{l}\text { Perfusion } \\
0.1 \mathrm{M} \mathrm{HCl}\end{array}$ & Rat & $(128)$ \\
\hline Skin & $\begin{array}{l}1 \% \text { SDS and } 0.5 \% \text { pen/strep } \\
\text { Isopropyl alcohol } \\
0.001 \% \text { Triton } \mathrm{X}-100\end{array}$ & $\begin{array}{l}\text { Perfusion } \\
0.1 \mathrm{M} \mathrm{HCl}\end{array}$ & Murine & (30) \\
\hline Nerve & $\begin{array}{l}3.0 \% \text { Triton } \mathrm{X}-100 \\
4.0 \% \mathrm{SDS}\end{array}$ & $\begin{array}{l}0.01 \mathrm{M} \mathrm{HCl} \\
0.1 \mathrm{M} \mathrm{NaOH}\end{array}$ & Porcine & (84) \\
\hline Skeletal muscle & $\begin{array}{l}0.7 \% \mathrm{NaCl} \\
1 \% \text { Triton } \mathrm{X}-100 \\
70 \% \text { ethanol }\end{array}$ & $\begin{array}{l}\text { Perfusion } \\
0.02 \mathrm{M} \mathrm{HCl} \\
24 \mathrm{~h}\end{array}$ & Mouse & (129) \\
\hline
\end{tabular}

Perfusion involved i) Triton X-100 + SDS; ii) stir plate, RT, at least 48 h; iii) neutralized to pH 7.4 and physiological salt with NaOH and $10 \mathrm{X}$ PBS.

the stability of reconstituted gels at neutral $\mathrm{pH}$. Nucleases, including DNases and RNases, are used to cleave nucleic acid sequences after cell lysis in tissues. Recent findings have shown that intervertebral discs subjected to treatment with $0.02 \mathrm{mg} / \mathrm{ml}$ DNase and $20 \mathrm{mg} / \mathrm{ml}$ RNAse, not only removed DNA residual at acceptable levels of less than $50 \mathrm{ng} / \mathrm{mg}$ dry weight, but also markedly reduced the total processing time of ECM digestion (52). Lipase specifically targets ester bond of triglycerides to hydrolyze lipase into glycerol and fatty acids. Thus, it is widely used for digesting lipase from fatty tissues, including intestinal mucosa, human nerve and heart. In addition, heparinases and hyaluronidase aid in releasing grow th factors, exposing proteins such as surface receptors and decreasing the water binding capacity (happening also in arthritic conditions). Overall, adding enzyme as the final step for solubilizing decellularized tissue may be desirable or even necessary, particularly for complete removal of cell residues or undesirable ECM constituents from dense tissues.

\section{Removal of residual cellular components and chemicals}

It is well known that to prepare proper ECM hydrogel after decellularization and solubilization, it is required to ensure the removal of undesired materials and decellularization agents as much as possible, while mostly retaining the desired ECM components and native architectures as well (53). The undesirable residual cellular materials include cellular-derived DNA, endotoxins, xenoantigens and pathogenic contaminations, as well as the decellularization agents mentioned in the above chapter. The residual cellular-derived DNA can be regarded as undesirable remnants of decellularization rather than an accurate and reliable representative universal reporter of cellular contamination (54). Current reports of minimal criteria for acceptable amounts of residual DNA in biologic ECM hydrogel is less than $50 \mathrm{ng} / \mathrm{mg}$ of dry product with fragment length of less than $300 \mathrm{bp}$ (55), which can be detected simply through commercial dye-based optometric assays or other histologic staining techniques. As contaminants in biologically derived materials, endotoxins have the potent ability to stimulate acute inflammatory responses for different cell types with varying threshold levels of contamination. Presently, the US FDA has stipulated that the detection limit of endotoxins in all medical devices, including hydrogels made from decellularized tissues, need to meet the requirement of less than $0.5 \mathrm{EU} / \mathrm{ml}$ (56). Based on the fact that endotoxin determinations are required for ECM-derived materials, the use of commercialized limulus amebocyte lysate test has been accepted as a highly sensitive and accurate method for assessing the safety of a wider range of ECM-P (57). Xenoantigens, including $\alpha$-gal and MHC-I, are the two major extracellular components presented in the purified ECM-G. When applied in clinical studies, these two antigens could promote recruitment and activation of immune cells, such as T-cells and B-cells, to secrete a large number of cytokines and chemokines that strongly invoked implant rejection and a host response (58). Thus, these xenoantigens should be eliminated from the prepared ECM-G as much as possible. Besides xenogenic cellular antigens, residual chemicals in the decellularized materials is also an important concern.

The decellularization steps involve the utilization of a wide variety of chemical agents. These residual chemicals within the ECM-G are mainly various non-ionic and ionic solutions, including Triton X-100 and SDS (10). A high concentration of 
these residual chemicals within the ECM-G will most likely provoke an adverse host tissue response and lead to cytotoxicity (59). Thus, care must be taken to flush residual chemicals away from ECM-G after decellularization. As these residual chemicals have high affinity with ECM-related proteins, there is no optimal method for the complete removal of these residual chemicals, except for persistent washing steps with sterile water (59). As such, we need to create a useful detergent that has the capability of absorbing these residual chemicals and develop a standardized analytical technique that can accurately detect the presence of chemicals after decellularization.

\section{Application of ECM-P in regenerative medicine}

In recent years, the use of ECM-P for surgical applications has become increasingly prevalent, especially for the field of nerve regeneration and bone repair (60). It is well known that ECM-P contain a complex meshwork of proteins and polysaccharides, which provides biochemical support to the surrounding cells for promoting their survival, proliferation and differentiation (61). Moreover, they also possess an intact three-dimensional structure and a certain intrinsic mechanical property, which contribute to creating an optical microenvironment for wound healing and tissue remodeling (62). Additionally, they are used as in vitro cell culture platforms for seeding and differentiating stem cells into tissue- and organ-specific cells, or regarded as a bio-therapeutic vehicle capable of delivering GFs or cytokines to control their release in a steady manner at the local site of action $(3,63)$. Thus, ECM-P have been used in different ways and combinations for guiding cell regrowth and tissue repair. The applications of ECM-P for numerous pre-clinical and clinical restoration of dysfunctional cells/tissues are described in the following subsections.

Cellular response to ECM-P. The ECM-P are composed of various distinct components that create a permissive environment for cell spreading, migration, proliferation, and differentiation. They also regulate cellular phenotype and behavior in various forms. Emerging researches and preliminary clinical studies have used this matrix for 3D cell culture. For instance, when human mesenchymal stem cells were encapsulated into a hydrogel with interpenetrating network to form a 3D culture model, the components of collagen and fibrillar could interact with the stem cell surface receptors, CD44 and RHAMM15, to support their spreading and focal adhesion formation (64). Furthermore, the combination of human umbilical cord mesenchymal stem cells and umbilical vein endothelial cells in a $3 \mathrm{D}$ co-culture system formed by photocrosslinking GelMA hydrogel efficiently stimulated cell proliferation and differentiation as well as vascularization (65). Besides acting as the 3D culture platforms, ECM-P are also proposed for the construction of bioinks for tissue 3D printing. Lee and colleagues constructed a highly accurate human heart model which enabled rapid cellular infiltration and microvascularization using the freeform reversible embedding of suspended hydrogels via 3D-bioprinting technique (66). Spatial organization of cardiac progenitor cells into porcine left ventricle tissue-derived decellularized extracellular matrix bioink using 3D cell printing method could effectively facilitate cell survival and differentiation, and improve cell-to-cell interactions, resulting in beneficial effects on reducing cardiac hypertrophy and fibrosis along with improving cardiac function after patch transplantation (67). ECM hydrogels incorporated with stem cells hold great promise for the formation and growth of human organoids which can be applied as a therapeutic tool for various disease models. The earliest report identified intestinal organoid formation through expansion of mouse and human intestinal stem cell matrices in an appropriate 3D matrix hydrogel (68). Subsequently, the use of ECM hydrogels derived from decellularized porcine small intestine mucosa endodermal organoid has the advantage for providing a structural support and biochemical signals to enable formation and growth of endoderm-derived human organoids, including hepatic, pancreatic, and small intestine (2). Similarly, Saheli et al reported that a 3D sheep liver-derived ECM hydrogel has the capability to tailor the biochemical and biophysical microenvironment for inducing a functional liver organoids generation by co-culturing human hepatocarcinoma cells, human mesenchymal and endothelial cells at a 3:2:1 ratio (69). Therefore, hydrogel-based organoid morphogenesis has been employed for the construction of $3 \mathrm{D}$ tissue models in vitro to revolutionize biomedical research and drug development.

Although 3D organotypic construct has provided a suitable platform for potential applications in imitating disease modeling and organ development, as well as regenerative medicine, there are some obstacles that need to be overcome. One major issue is low reproducibility of organoids and limited capability of differentiation into special tissue and organ types (70). It is well known that cell expansion, differentiation and self-organization are mainly dependent on inherent genetic reprogramming and external microenvironmental cues, such as distinct biochemical and biophysical factors $(71,72)$. To reproducibly and accurately recapitulate the expansion and differentiation of specific organoids, emerging solutions adopted gene reprogramming technology to directly alter specific gene of DNA in stem cells or utilized engineering approaches to precisely control cell-matrix interactions, nutrient supply and the local stiffness of the organoids formation $(73,74)$. Another issue is the lack of vascular system during the generation of organoids (72). Neovascularization is of great importance for maintaining tissue oxygenation and fluid homeostasis. This problem may be solved by utilizing prevascularized scaffolds from matrix hydrogels modules via sacrificial printing (75).

It should be noted that ECM-P sourced from different tissues/organs contained some specific molecules that play an important role in cell phenotype and behavior (21). Logically, the native ECM-P of the homologous tissue or organ sources have superior biological property for inducing cell survival, proliferation and differentiation, as well as exerting multiple regenerative medicine therapies (3). It has been reported that the canine sciatic nerve-specific extracellular matrix-based hydrogel had the inherent ability to increase the M2 macrophage ratio and enhance Schwann cell migration, leading to functional recovery and nerve repair in a rodent nerve gap defect model (76). In addition, results of a study by Keane et al showed that a homologous esophageal ECM-gel derived from small intestinal submucosa had more biological advantage in enhancing the migration of esophageal stem cells and the 
formation of 3D organoids than that of the non-homologous ECM-gel isolated from urinary bladder (77). These outcomes indicated that the site-specific or homologous ECM hydrogel could provide a set of tissue-specific matrix and cell-secreted molecules for promoting site-appropriate differentiation of stem cells and maintaining site appropriate phenotype in vitro.

ECM-P for preclinical applications. The decellularized tissue materials inherit various biochemical components that are favorable for organ development, tissue repair, and wound healing. Currently, ECM-P have been successfully used in a variety of pre-clinical animal model studies, such as spinal cord injury (SCI), peripheral nerve regeneration, myocardial repair, and so on $(1,78)$. The reason for ECM-P serving as a suitable substitute for damaged tissue restoration is their ability to provide a native tissue microenvironment for coexisting and interacting with specific body tissues or physiological systems without provoking strong immune and toxicity responses. Besides these unique properties, numerous proteins including collagen, elastin, fibrillin, and fibulin in the ECM-P also activate a series of downstream signals of PI3K/AKT, MEK/ERK and/or Rho A/ROCK to exert their biological effect via binding to cell surface receptors (79-81). In additional, associated macromolecular non-protein glycosaminoglycans found in the ECM-P reversibly adsorb GFs and cytokines, expanding their application for tissue morphogenesis and organ development. Presently, we will discuss ECM-P for preclinical applications through two main aspects: The nerves and the heart.

The adult nervous system, classified into the central (CNS) and peripheral (PNS) regions, initiates a biological response via receiving internal and external stimuli on the neuronal membrane. As the longest and thickest nerve in the PNS, sciatic nerve arranges the movement and sensation of leg and foot muscle. If sciatic nerve suffered from traumatic injury, surgery or compression, the partial or total loss of motor, sensory, and autonomic functions are bound to happen, leading to restricted activity and affecting the quality of life for clinical patients (82). An established strategy for therapeutic interventions is using ECM-P, such as ECM-based conduit or scaffold incorporated with/without GFs or macromolecules, to implant into the lesion region (83). This technique, not only provides mechanical support for cell adhesion, but also produces insoluble microenvironmental cues for improving nerve functional recovery. Thus, this material is used widely for peripheral nerve regeneration. A decellularized porcine nerve matrix hydrogel could support SC proliferation in vitro and promote axon regeneration, myelination, and functional recovery when combined with electrospun conduits together to repair 15-mm rat sciatic nerve defect model in vivo (84). Shuai et al have successfully developed a human decellularized nerve scaffold via combining decellularized nerve matrix hydrogel and glial-derived neurotrophic factor together and applying it to bridge a $50 \mathrm{~mm}$ sciatic nerve defect in a beagle model. The result showed that this nerve scaffold had excellent effects on promoting motor function recovery and nerve tissue remodeling (85). Additionally, studies have confirmed that alginate/hyaluronic acid 3D scaffold was used successfully to direct the differentiation of encapsulated gingival mesenchymal stem cells towards neurogenic tissues for nerve regeneration therapies (86). Overall, these biological ECM-P derived from mammal sciatic nerve showed various structural and functional characteristics for enhancing peripheral nerve regeneration.

The CNS trauma, including traumatic brain injury (TBI) and SCI, initiates a cascade of changes at both cellular and molecular level, which disturbs the microenvironmental homeostasis, impairs axon regeneration and inhibits full functional recovery. Injectable hydrogel with appropriate mechanical properties has been applied most extensively for both injury models (22). It has been demonstrated that urinary bladder matrix hydrogel injection alone decreased lesion volume and myelin disruption, as well as improved neurobehavioral recovery following TBI (87). Further studies demonstrated that transplantation of proliferating neural stem cells in bioactive urinary bladder matrix hydrogel significantly ameliorated memory and cognitive impairments following TBI (88). Similarly, extensive findings also apply ECM-P for conducting SCI trial. It has been reported that injection of thermosensitive poly(organophosphazenes) hydrogel into the cystic cavities of injured spinal cord could support axon growth, reduce cavity volume and decrease locomotor deficit (89). Use of synthetic matrix materials, seen in a study by Hong et al, included PEGDA and GelMa been fabricated into a spinal cord scaffold via 3D printing (90). Their results showed significant improvements in motor functional outcome and axonal elongation from the lesion site into the distal host spinal cord.

Myocardial infarction (MI) is a term for an event of heart attack with an increased risk of morbidity and mortality (91). Porcine myocardial ECM hydrogel for treating progressive heart failure following MI has been investigated for recent regenerative therapy application, because this ECM material is capable of assembling into a nanofibrous network that allows cell migration and has tissue-specific cues that are in favor for appropriate cardiac tissue remodeling (92). For instance, decellularized myocardial matrix hydrogel has become an alternative option for MI treatment and achieved long-term functional stabilization and improvement in heart function (93). However, simple use of solubilized porcine myocardial ECM hydrogel for MI application has some problems, such as limited mechanical strength and rapid degradation (94). To overcome these limitations, Efraim et al presented a newly-developed injectable scaffold via cross-linking decellularized porcine cardiac extracellular matrix hydrogel with chitosan, which exhibited significant improvement for cardiac tissue regeneration when injected into rat hearts following acute and chronic MI (95). Moreover, use of nanocomposite hydrogel as a carrier for the delivery of the mesenchymal stem cells showed an efficient improvement in capillary density and myocardial regeneration, as well as reduction in scar area (96). Thus, incorporation of stem cell and/or cytokines within the myocardial ECM hydrogel represents a viable option for the treatment of acute myocardial infarction.

ECM-P for clinical applications. The use of allogeneic or xenogeneic ECM-P, which are commercially available for more than 20 years, have become a primary option for remodeling a variety of clinical tissues defects, such as the 
myocardium reconstruction, bone regeneration and nerve repair (3). Most commercial products from various ECM sources have been reviewed in depth elsewhere (97). Thus, we just list some of their therapeutic outcomes. One example for evaluating MI repair in clinical trials is myocardial ECM hydrogel (identifier: NCT02305602). This heterologous material had the ability to go through a cardiac injection catheter to enhance vascular cell infiltration and cardiomyocyte survival (98). In parallel, previous findings have shown that Avance ${ }^{\circledR}$ Nerve Graft (AxoGen Inc.) has been used to repair human sciatic nerve defect and achieve positive axon regrowth and motor functional recovery (99). Besides, a biocompatible hydrogel scaffold (Geistlich Pharma AG) isolated from the decellularized and demineralized bone has confirmed promising outcomes for repairing early and mid-term clinical osteochondral knee defects (100). The common features of these ECM-P for extensive applications of regenerative medicine can be categorized as follows: i) Preserving meshwork of native architecture and biologically active molecules; ii) excellent mechanical and structural profiles; iii) biodegradation and temperature-sensitive property; and iv) easily integrating with the native tissue by filling the irregular defects. In this sense, ECM-P have provided an efficient therapeutic approach to guide tissue regeneration and replacement.

\section{Challenges and future outlook on ECM-P}

Although ECM-P appear to have many advantages, there are some existing issues that need to be addressed. One problem is tissue homogeny. It has been shown that tissue sources, including the species, age, and specificity, can significantly alter tissue-specific cell phenotype and function (101). Therefore, selection of the proper hydrogel product is the precondition for clinical tissue reconstruction. Another issue is product size and shape. As the cavity region of damaged tissue is irregular, implantation of pre-formed scaffolds is usually inefficient (102). At this condition, injection of gelatinous liquid is probably more suitable for treating complex disease and injury models. Additionally, requirements may be completely different when ECM-P were used for replacing a heart valve or a piece of aorta, repairing wounds or defects in skin, mucosa, joints, or bones. Thus, the design of ECM-P needs to satisfy the specific requirements for different diseases. As ECM-P are becoming the alternative biomaterials for the regeneration and repair of damaged tissues, some of the current challenges can be overcome via developing international standards and good manufacturing practices.

\section{Conclusions}

Overall, this review sought to highlight the selection of an appropriate decellularized technique for improving biocompatibility and biomimetic properties in the ECM-P that are suitable for applying in regenerative medicine research. With regards to structural and compositional diversity, each kind of ECM-P from specific tissue or organ have their unique microenvironments and biochemical cues for inducing site-appropriate cellular growth and tissue regeneration. In the future, with the development of 3D bioprinting approach and computer-aided design technology, biocompatible ECM products are emerging as a promising artificial tissue substitutes with suitable mechanical and morphological characteristics for restoring damaged tissues or organ.

\section{Acknowledgements}

Not applicable.

\section{Funding}

This study was partially supported by a research grant from the National Natural Science Funding of China (81802238), Zhejiang Provincial Natural Science Foundation of China (LWQ20H170001).

\section{Availability of data and materials}

Not applicable.

\section{Authors' contributions}

YL, RL and $\mathrm{H}$ were involved in the conception of the study. $\mathrm{RL}, \mathrm{CH}$ and $\mathrm{LH}$ were involved in the literature search and critical reviewing of the manuscript. YJ and RL were involved in the preparation of the draft of the manuscript. All authors read and approved the final manuscript.

\section{Ethics approval and consent to participate}

Not applicable.

\section{Patient consent for publication}

Not applicable.

\section{Competing interests}

The authors confirm this article has no conflicts of interest.

\section{References}

1. Bonnans C, Chou J and Werb Z: Remodelling the extracellular matrix in development and disease. Nat Rev Mol Cell Biol 15: 786-801, 2014.

2. Giobbe GG, Crowley C, Luni C, Campinoti S, Khedr M, Kretzschmar K, De Santis MM, Zambaiti E, Michielin F, Meran L, et al: Extracellular matrix hydrogel derived from decellularized tissues enables endodermal organoid culture. Nat Commun 10: 5658, 2019.

3. Spang MT and Christman KL: Extracellular matrix hydrogel therapies: In vivo applications and development. Acta Biomater 68: 1-14, 2018.

4. Kraehenbuehl TP, Zammaretti P, Van der Vlies AJ, Schoenmakers RG, Lutolf MP, Jaconi ME and Hubbell JA: Three-dimensional extracellular matrix-directed cardioprogenitor differentiation: Systematic modulation of a synthetic cell-responsive PEG-hydrogel. Biomaterials 29: 2757-2766, 2008.

5. Ma Y, Ji Y, Huang G, Ling K, Zhang X and Xu F: Bioprinting $3 \mathrm{D}$ cell-laden hydrogel microarray for screening human periodontal ligament stem cell response to extracellular matrix. Biofabrication 7: 044105, 2015.

6. Aamodt JM and Grainger DW: Extracellular matrix-based biomaterial scaffolds and the host response. Biomaterials 86: 68-82, 2016. 
7. Vincent AT, Schiettekatte O, Goarant C, Neela VK, Bernet E, Thibeaux R, Ismail N, Mohd Khalid MKN, Amran F, Masuzawa T, et al: Revisiting the taxonomy and evolution of pathogenicity of the genus Leptospira through the prism of genomics. PLoS Negl Trop Dis 13: e0007270, 2019.

8. Szalewski DA, Hinrichs VS, Zinniel DK and Barletta RG: The pathogenicity of Aspergillus fumigatus, drug resistance, and nanoparticle delivery. Can J Microbiol 64: 439-453, 2018.

9. Zilelidou EA and Skandamis PN: Growth, detection and virulence of Listeria monocytogenes in the presence of other microorganisms: Microbial interactions from species to strain level. Int J Food Microbiol 277: 10-25, 2018.

10. Gilbert TW, Sellaro TL and Badylak SF: Decellularization of tissues and organs. Biomaterials 27: 3675-3683, 2006.

11. Choi JS, Yang HJ, Kim BS, Kim JD, Kim JY, Yoo B, Park K, Lee HY and Cho YW: Human extracellular matrix (ECM) powders for injectable cell delivery and adipose tissue engineering. J Control Release 139: 2-7, 2009.

12. Sackett SD, Tremmel DM, Ma F, Feeney AK, Maguire RM, Brown ME, Zhou Y, Li X, O'Brien C, Li L, et al: Extracellular matrix scaffold and hydrogel derived from decellularized and delipidized human pancreas. Sci Rep 8: 10452, 2018.

13. Lv S, Bu T, Kayser J, Bausch A and Li H: Towards constructing extracellular matrix-mimetic hydrogels: An elastic hydrogel constructed from tandem modular proteins containing tenascin FnIII domains. Acta Biomater 9: 6481-6491, 2013.

14. Rao N, Agmon G, Tierney MT, Ungerleider JL, Braden RL, Sacco A and Christman KL: Engineering an injectable muscle-specific microenvironment for improved cell delivery using a nanofibrous extracellular matrix hydrogel. ACS Nano 11: 3851-3859, 2017

15. Seif-Naraghi SB, Horn D, Schup-Magoffin PJ and Christman KL: Injectable extracellular matrix derived hydrogel provides a platform for enhanced retention and delivery of a heparin-binding growth factor. Acta Biomater 8: 3695-3703, 2012.

16. Davidov T, Efraim Y, Dahan N, Baruch L and Machluf M: Porcine arterial ECM hydrogel: Designing an in vitro angiogenesis model for long-term high-throughput research. FASEB J 34: $7745-7758,2020$

17. Rosso F, Giordano A, Barbarisi M and Barbarisi A: From cell-ECM interactions to tissue engineering. J Cell Physiol 199: 174-180, 2004.

18. Engler AJ, Sen S, Sweeney HL and Discher DE: Matrix elasticity directs stem cell lineage specification. Cell 126: 677-689, 2006.

19. Divya P and Krishnan LK: Glycosaminoglycans restrained in a fibrin matrix improve ECM remodelling by endothelial cells grown for vascular tissue engineering. J Tissue Eng Regen Med 3: 377-388, 2009.

20. Kim SH, Lee SH, Lee JE, Park SJ, Kim K, Kim IS, Lee YS Hwang NS and Kim BG: Tissue adhesive, rapid forming, and sprayable ECM hydrogel via recombinant tyrosinase crosslinking. Biomaterials 178: 401-412, 2018.

21. Wu J, Ding Q, Dutta A, Wang Y, Huang YH, Weng H, Tang L and Hong Y: An injectable extracellular matrix derived hydrogel for meniscus repair and regeneration. Acta Biomater 16: 49-59, 2015.

22. Tukmachev D, Forostyak S, Koci Z, Zaviskova K, Vackova I, Vyborny K, Sandvig I, Sandvig A, Medberry CJ, Badylak SF, et al: Injectable extracellular matrix hydrogels as scaffolds for spinal cord injury repair. Tissue Eng Part A 22: 306-317, 2016.

23. Ahearne M: Introduction to cell-hydrogel mechanosensing. Interface Focus 4: 20130038, 2014.

24. Vats K and Benoit DS: Dynamic manipulation of hydrogels to control cell behavior: a review. Tissue Eng Part B Rev 19: 455-469, 2013

25. Ghuman H, Mauney C, Donnelly J, Massensini AR, Badylak SF and Modo M: Biodegradation of ECM hydrogel promotes endogenous brain tissue restoration in a rat model of stroke. Acta Biomater 80: 66-84, 2018.

26. Black C, Kanczler JM, de Andres MC, White LJ, Savi FM, Bas O, Saifzadeh S, Henkel J, Zannettino A, Gronthos S, et al: Characterisation and evaluation of the regenerative capacity of Stro-4+ enriched bone marrow mesenchymal stromal cells using bovine extracellular matrix hydrogel and a novel biocompatible melt electro-written medical-grade polycaprolactone scaffold. Biomaterials 247: 119998, 2020.

27. Wang Y, Gallant RC and Ni H: Extracellular matrix proteins in the regulation of thrombus formation. Curr Opin Hematol 23: 280-287, 2016
28. Jiang B, Suen R, Wertheim JA and Ameer GA: Targeting heparin to collagen within extracellular matrix significantly reduces thrombogenicity and improves endothelialization of decellularized tissues. Biomacromolecules 17: 3940-3948, 2016.

29. Li X, Zhang C, Haggerty AE, Yan J, Lan M, Seu M, Yang M, Marlow MM, Maldonado-Lasunción I, Cho B, et al: The effect of a nanofiber-hydrogel composite on neural tissue repair and regeneration in the contused spinal cord. Biomaterials 245: 119978, 2020.

30. Farrokhi A, Pakyari M, Nabai L, Pourghadiri A, Hartwell R, Jalili R and Ghahary A: Evaluation of detergent-free and detergent-based methods for decellularization of murine skin. Tissue Eng Part A 24: 955-967, 2018.

31. Gupta SK, Mishra NC and Dhasmana A: Decellularization methods for scaffold fabrication. Methods Mol Biol 1577: 1-10, 2018

32. isidan A, Liu S, Li P, Lashmet M, Smith LJ, Hara H, Cooper DKC and Ekser B: Decellularization methods for developing porcine corneal xenografts and future perspectives. Xenotransplantation 26: e12564, 2019.

33. Jackson DW, Grood ES, Arnoczky SP, Butler DL and Simon TM: Freeze dried anterior cruciate ligament allografts. Preliminary studies in a goat model. Am J Sports Med 15: 295-303, 1987.

34. Jackson DW, Grood ES, Wilcox P, Butler DL, Simon TM and Holden JP: The effects of processing techniques on the mechanical properties of bone-anterior cruciate ligament-bone allografts. An experimental study in goats. Am J Sports Med 16: 101-105, 1988.

35. Mardhiyah A, Sha'ban M and Azhim A: Evaluation of histological and biomechanical properties on engineered meniscus tissues using sonication decellularization. Annu Int Conf IEEE Eng Med Biol Soc 2017: 2064-2067, 2017.

36. Hrebikova H, Diaz D and Mokry J: Chemical decellularization: A promising approach for preparation of extracellular matrix. Biomed Pap Med Fac Univ Palacky Olomouc Czech Repub 159: $12-17,2015$.

37. Tchoukalova YD, Hintze JM, Hayden RE and Lott DG: Tracheal decellularization using a combination of chemical, physical and bioreactor methods. Int J Artif Organs: Sep 28, 2017 (Epub ahead of print). doi: 10.5301/ijao.5000648.

38. Jiang WC, Cheng YH, Yen MH, Chang Y, Yang VW and Lee OK: Cryo-chemical decellularization of the whole liver for mesenchymal stem cells-based functional hepatic tissue engineering. Biomaterials 35: 3607-3617, 2014.

39. McCrary MW, Vaughn NE, Hlavac N, Song YH, Wachs RA and Schmidt CE: Novel sodium deoxycholate-based chemical decellularization method for peripheral nerve. Tissue Eng Part C Methods 26: 23-36, 2020.

40. Tebyanian H, Karami A, Motavallian E, Aslani J, Samadikuchaksaraei A, Arjmand B and Nourani MR: Histologic analyses of different concentrations of tritonX-100 and Sodium dodecyl sulfate detergent in lung decellularization. Cell Mol Biol (Noisy-le-grand) 63: 46-51, 2017.

41. Vafaee T, Thomas D, Desai A, Jennings LM, Berry H, Rooney P, Kearney J, Fisher J and Ingham E: Decellularization of human donor aortic and pulmonary valved conduits using low concentration sodium dodecyl sulfate. J Tissue Eng Regen Med 12: e841-e853, 2018

42. Yu BT, Li WT, Song BQ and Wu YL: Comparative study of the triton X-100-sodium deoxycholate method and detergent-enzymatic digestion method for decellularization of porcine aortic valves. Eur Rev Med Pharmacol Sci 17: 2179-2184, 2013.

43. Varhac R, Robinson NC and Musatov A: Removal of bound triton X-100 from purified bovine heart cytochrome bc1. Anal Biochem 395: 268-270, 2009.

44. Dahl SL, Koh J, Prabhakar V and Niklason LE: Decellularized native and engineered arterial scaffolds for transplantation. Cell Transplant 12: 659-666, 2003.

45. Chen RN, Ho HO, Tsai YT and Sheu MT: Process development of an acellular dermal matrix (ADM) for biomedical applications. Biomaterials 25: 2679-2686, 2004.

46. Goissis G, Suzigan S, Parreira DR, Maniglia JV, Braile DM and Raymundo S: Preparation and characterization of collagen-elastin matrices from blood vessels intended as small diameter vascular grafts. Artif Organs 24: 217-223, 2000.

47. Gamba PG, Conconi MT, Lo Piccolo R, Zara G, Spinazzi R and Parnigotto PP: Experimental abdominal wall defect repaired with acellular matrix. Pediatr Surg Int 18: 327-331, 2002.

48. McFetridge PS, Daniel JW, Bodamyali T, Horrocks $M$ and Chaudhuri JB: Preparation of porcine carotid arteries for vascular tissue engineering applications. J Biomed Mater Res A 70: 224-234, 2004. 
49. Teebken OE, Bader A, Steinhoff G and Haverich A: Tissue engineering of vascular grafts: Human cell seeding of decellularised porcine matrix. Eur J Vasc Endovasc Surg 19: 381-386, 2000.

50. Rahman S, Griffin M, Naik A, Szarko M and Butler PEM: Optimising the decellularization of human elastic cartilage with trypsin for future use in ear reconstruction. Sci Rep 8: 3097, 2018.

51. Warwick RM, Magee JG, Leeming JP, Graham JC, Hannan MM, Chadwick M, Crook DW, Yearsley CP, Rayner A and Parker R Mycobacteria and allograft heart valve banking: An international survey. J Hosp Infect 68: 255-261, 2008.

52. Hensley A, Rames J, Casler V, Rood C, Walters J, Fernandez C, Gill S and Mercuri JJ: Decellularization and characterization of a whole intervertebral disk xenograft scaffold. J Biomed Mater Res A 106: 2412-2423, 2018.

53. Crapo PM, Gilbert TW and Badylak SF: An overview of tissue and whole organ decellularization processes. Biomaterials 32 : 3233-3243, 2011.

54. Wong ML and Griffiths LG: Immunogenicity in xenogeneic scaffold generation: Antigen removal vs. Decellularization. Acta Biomater 10: 1806-1816, 2014.

55. Nagata S, Hanayama R and Kawane K: Autoimmunity and the clearance of dead cells. Cell 140: 619-630, 2010.

56. Dullah EC and Ongkudon CM: Current trends in endotoxin detection and analysis of endotoxin-protein interactions. Crit Rev Biotechnol 37: 251-261, 2017.

57. Ogikubo Y, Norimatsu M, Noda K, Takahashi J, Inotsume M, Tsuchiya M and Tamura Y: Evaluation of the bacterial endotoxin test for quantification of endotoxin contamination of porcine vaccines. Biologicals 32: 88-93, 2004.

58. Yang YG and Sykes M: Xenotransplantation: Current status and a perspective on the future. Nat Rev Immunol 7: 519-531, 2007

59. Aurora A, McCarron J, Iannotti JP and Derwin K: Commercially available extracellular matrix materials for rotator cuff repairs: State of the art and future trends. J Shoulder Elbow Surg 16 (Suppl 5): S171-S178, 2007.

60. Ercan H, Durkut S, Koc-Demir A, Elçin AE and Elçin YM: Clinical applications of injectable biomaterials. Adv Exp Med Biol 1077: 163-182, 2018

61. Ahmadian Z, Correia A, Hasany M, Figueiredo P, Dobakhti F, Eskandari MR, Hosseini SH, Abiri R, Khorshid S, Hirvonen J, et al: A hydrogen-bonded extracellular matrix-mimicking bactericidal hydrogel with radical scavenging and hemostatic function for $\mathrm{pH}$-responsive wound healing acceleration. Adv Healthc Mater: Oct 26, 2020 (Epub ahead of print). doi: 10.1002/ adhm.202001122.

62. Ha DH, Chae S, Lee JY, Kim JY, Yoon J, Sen T, Lee SW, Kim HJ, Cho JH and Cho DW: Therapeutic effect of decellularized extracellular matrix-based hydrogel for radiation esophagitis by 3D printed esophageal stent. Biomaterials 266: 120477, 2021.

63. Beachley V, Ma G, Papadimitriou C, Gibson M, Corvelli M and Elisseeff J: Extracellular matrix particle-glycosaminoglycan composite hydrogels for regenerative medicine applications. J Biomed Mater Res A 106: 147-159, 2018.

64. Lou J, Stowers R, Nam S, Xia Y and Chaudhuri O: Stress relaxing hyaluronic acid-collagen hydrogels promote cell spreading, fiber remodeling, and focal adhesion formation in 3D cell culture. Biomaterials 154: 213-222, 2018.

65. Zhang X, Li J, Ye P, Gao G, Hubbell K and Cui X: Coculture of mesenchymal stem cells and endothelial cells enhances host tissue integration and epidermis maturation through AKT activation in gelatin methacryloyl hydrogel-based skin model. Acta Biomater 59: 317-326, 2017.

66. Lee A, Hudson AR, Shiwarski DJ, Tashman JW, Hinton TJ, Yerneni S, Bliley JM, Campbell PG and Feinberg AW: 3D bioprinting of collagen to rebuild components of the human heart. Science 365: 482-487, 2019.

67. Jang J, Park HJ, Kim SW, Kim H, Park JY, Na SJ, Kim HJ, Park MN, Choi SH, Park SH, et al: 3D printed complex tissue construct using stem cell-laden decellularized extracellular matrix bioinks for cardiac repair. Biomaterials 112: 264-274, 2017.

68. Gjorevski N, Sachs N, Manfrin A, Giger S, Bragina ME, Ordóñez-Morán P, Clevers H and Lutolf MP: Designer matrices for intestinal stem cell and organoid culture. Nature 539: 560-564, 2016.

69. Saheli M, Sepantafar M, Pournasr B, Farzaneh Z, Vosough M, Piryaei $\mathrm{A}$ and Baharvand $\mathrm{H}$ : Three-dimensional liver-derived extracellular matrix hydrogel promotes liver organoids function. J Cell Biochem 119: 4320-4333, 2018.
70. Broguiere N, Isenmann L, Hirt C, Ringel T, Placzek S, Cavalli E, Ringnalda F, Villiger L, Züllig R, Lehmann R, et al: Growth of epithelial organoids in a defined hydrogel. Adv Mater 30: e1801621, 2018

71. Augsornworawat P, Velazco-Cruz L, Song J and Millman JR: A hydrogel platform for in vitro three dimensional assembly of human stem cell-derived islet cells and endothelial cells. Acta Biomater 97: 272-280, 2019.

72. Liu H, Wang Y, Cui K, Guo Y, Zhang X and Qin J: Advances in hydrogels in organoids and organs-on-a-chip. Adv Mater 31: e1902042, 2019.

73. Chuang W, Sharma A, Shukla P, Li G, Mall M, Rajarajan K, Abilez OJ, Hamaguchi R, Wu JC, Wernig M and Wu SM: Partial reprogramming of pluripotent stem cell-derived cardiomyocytes into neurons. Sci Rep 7: 44840, 2017.

74. Garreta E, Prado P, Tarantino C, Oria R, Fanlo L, Martí E, Zalvidea D, Trepat X, Roca-Cusachs $\mathrm{P}$, Gavaldà-Navarro A, et al: Fine tuning the extracellular environment accelerates the derivation of kidney organoids from human pluripotent stem cells. Nat Mater 18: 397-405, 2019.

75. Gong J, Schuurmans CCL, Genderen AMV, Cao X, Li W, Cheng F, He JJ, López A, Huerta V, Manríquez J, et al: Complexation-induced resolution enhancement of 3D-printed hydrogel constructs. Nat Commun 11: 1267, 2020.

76. Prest TA, Yeager E, LoPresti ST, Zygelyte E, Martin MJ, Dong L, Gibson A, Olutoye OO, Brown BN and Cheetham J: Nerve-specific, xenogeneic extracellular matrix hydrogel promotes recovery following peripheral nerve injury. J Biomed Mater Res A 106: 450-459, 2018.

77. Keane TJ, DeWard A, Londono R, Saldin LT, Castleton AA Carey L, Nieponice A, Lagasse E and Badylak SF: Tissue-specific effects of esophageal extracellular matrix. Tissue Eng Part A 21: 2293-2300, 2015

78. Schnellmann R and Chiquet-Ehrismann R: Preparation and application of a decellularized extracellular matrix for identification of ADAMTS substrates. Methods Mol Biol 2043: 275-284, 2020.

79. Li R, Li Y, Wu Y, Chen H, Yuan Y, Xu K, Zhang H, Lu Y, Wang J, Li X, et al: Heparin-poloxamer thermosensitive hydrogel loaded with bFGF and NGF enhances peripheral nerve regeneration in diabetic rats. Biomaterials 168: 24-37, 2018

80. Slivka PF, Dearth CL, Keane TJ, Meng FW, Medberry CJ, Riggio RT, Reing JE and Badylak SF: Fractionation of an ECM hydrogel into structural and soluble components reveals distinctive roles in regulating macrophage behavior. Biomater Sci 2: 1521-1534, 2014

81. Panorchan P, Lee JS, Kole TP, Tseng Y and Wirtz D: Microrheology and ROCK signaling of human endothelial cells embedded in a 3D matrix. Biophys J 91: 3499-3507, 2006.

82. Sjöberg $J$ and Kanje M: The initial period of peripheral nerve regeneration and the importance of the local environment for the conditioning lesion effect. Brain Res 529: 79-84, 1990.

83. Grinsell D and Keating CP: Peripheral nerve reconstruction after injury: A review of clinical and experimental therapies. Biomed Res Int 2014: 698256, 2014.

84. Lin T, Liu S, Chen S, Qiu S, Rao Z, Liu J, Zhu S, Yan L, Mao H, Zhu Q, et al: Hydrogel derived from porcine decellularized nerve tissue as a promising biomaterial for repairing peripheral nerve defects. Acta Biomater 73: 326-338, 2018.

85. Qiu S, Rao Z, He F, Wang T, Xu Y, Du Z, Yao Z, Lin T, Yan L, Quan D, et al: Decellularized nerve matrix hydrogel and glial-derived neurotrophic factor modifications assisted nerve repair with decellularized nerve matrix scaffolds. J Tissue Eng Regen Med 14: 931-943, 2020.

86. Ansari S, Diniz IM, Chen C, Sarrion P, Tamayol A, Wu BM and Moshaverinia A: Human periodontal ligament- and gingiva-derived mesenchymal stem cells promote nerve regeneration when encapsulated in alginate/hyaluronic acid 3D scaffold. Adv Healthc Mater 6: 10, 2017.

87. Zhang L, Zhang F, Weng Z, Brown BN, Yan H, Ma XM, Vosler PS, Badylak SF, Dixon CE, Cui XT and Chen J: Effect of an inductive hydrogel composed of urinary bladder matrix upon functional recovery following traumatic brain injury. Tissue Eng Part A 19: 1909-1918, 2013

88. Wang JY, Liou A, Ren ZH, Zhang L, Brown BN, Cui XT, Badylak SF, Cai YN, Guan YQ, Leak RK, et al: Neurorestorative effect of urinary bladder matrix-mediated neural stem cell transplantation following traumatic brain injury in rats. CNS Neurol Disord Drug Targets 12: 413-425, 2013. 
89. Buckenmeyer MJ, Meder TJ, Prest TA and Brown BN Decellularization techniques and their applications for the repair and regeneration of the nervous system. Methods 171: $41-61,2020$.

90. Hong LT, Kim YM, Park HH, Hwang DH, Cui Y, Lee EM, Yahn S, Lee JK, Song SC and Kim BG: An injectable hydrogel enhances tissue repair after spinal cord injury by promoting extracellular matrix remodeling. Nat Commun 8: 533, 2017.

91. Jiang X, Yang Z and Dong M: Cardiac repair in a murine model of myocardial infarction with human induced pluripotent stem cell-derived cardiomyocytes. Stem Cell Res Ther 11: 297, 2020.

92. Farnebo S, Woon CY, Schmitt T, Joubert LM, Kim M, Pham H and Chang J: Design and characterization of an injectable tendon hydrogel: A novel scaffold for guided tissue regeneration in the musculoskeletal system. Tissue Eng Part A 20: 1550-1561, 2014.

93. Curley CJ, Dolan EB, Otten M, Hinderer S, Duffy GP and Murphy BP: An injectable alginate/extra cellular matrix (ECM) hydrogel towards acellular treatment of heart failure. Drug Deliv Transl Res 9: 1-13, 2019.

94. Grover GN, Rao N and Christman KL: Myocardial matrix-polyethylene glycol hybrid hydrogels for tissue engineering. Nanotechnology 25: 014011, 2014.

95. Efraim Y, Sarig H, Cohen Anavy N, Sarig U, de Berardinis E, Chaw SY, Krishnamoorthi M, Kalifa J, Bogireddi H, Duc TV, et al: Biohybrid cardiac ECM-based hydrogels improve long term cardiac function post myocardial infarction. Acta Biomater 50: 220-233, 2017.

96. Waters R, Alam P, Pacelli S, Chakravarti AR, Ahmed RP and Paul A: Stem cell-inspired secretome-rich injectable hydrogel to repair injured cardiac tissue. Acta Biomater 69: 95-106, 2018.

97. Guruswamy Damodaran R and Vermette P: Tissue and organ decellularization in regenerative medicine. Biotechnol Prog 34: 1494-1505, 2018.

98. Seif-Naraghi SB, Salvatore MA, Schup-Magoffin PJ, Hu DP and Christman KL: Design and characterization of an injectable pericardial matrix gel: A potentially autologous scaffold for cardiac tissue engineering. Tissue Eng Part A 16: 2017-2027, 2010.

99. Karabekmez FE, Duymaz A and Moran SL: Early clinical outcomes with the use of decellularized nerve allograft for repair of sensory defects within the hand. Hand (NY) 4: 245-249, 2009.

100. Pipino G, Risitano S, Alviano F, Wu EJ, Bonsi L, Vaccarisi DC and Indelli PF: Microfractures and hydrogel scaffolds in the treatment of osteochondral knee defects: A clinical and histological evaluation. J Clin Orthop Trauma 10: 67-75, 2019.

101. Fitzpatrick LE and McDevitt TC: Cell-derived matrices for tissue engineering and regenerative medicine applications. Biomater Sci 3: 12-24, 2015 .

102. Loh QL and Choong C: Three-dimensional scaffolds for tissue engineering applications: Role of porosity and pore size. Tissue Eng Part B Rev 19: 485-502, 2013.

103. Defrere $\mathbf{J}$ and Franckart A: Freeze-dried fascia lata allografts in the reconstruction of anterior cruciate ligament defects. A two- to seven-year follow-up study. Clin Orthop Relat Res 303 56-66, 1994

104. Mahirogullari M, Ferguson CM, Whitlock PW, Stabile KJ and Poehling GG: Freeze-dried allografts for anterior cruciate ligament reconstruction. Clin Sports Med 26: 625-637, 2007.

105. Jackson DW, Grood ES, Cohn BT, Arnoczky SP, Simon TM and Cummings JF: The effects of in situ freezing on the anterior cruciate ligament. An experimental study in goats. J Bone Joint Surg Am 73: 201-213, 1991.

106. Freytes DO, Badylak SF, Webster TJ, Geddes LA and Rundell AE: Biaxial strength of multilaminated extracellular matrix scaffolds. Biomaterials 25: 2353-2361, 2004.

107. Lin P, Chan WC, Badylak SF and Bhatia SN: Assessing porcine liver-derived biomatrix for hepatic tissue engineering. Tissue Eng 10: 1046-1053, 2004.

108. Schenke-Layland K, Vasilevski O, Opitz F, Opitz F, König K, Riemann I, Halbhuber KJ, Wahlers T and Stock UA: Impact of decellularization of xenogeneic tissue on extracellular matrix integrity for tissue engineering of heart valves. J Struct Biol 143: 201-208, 2003.

109. Ott HC, Matthiesen TS, Goh SK, Black LD, Kren SM, Netoff TI and Taylor DA: Perfusion-decellularized matrix: Using nature's platform to engineer a bioartificial heart. Nat Med 14: 213-221, 2008.

110. Uygun BE, Soto-Gutierrez A, Yagi H, Izamis ML, Guzzardi MA, Shulman C, Milwid J, Kobayashi N, Tilles A, Berthiaume F, et al: Organ reengineering through development of a transplantable recellularized liver graft using decellularized liver matrix. Nat Med 16: 814-820, 2010.
111. Brown BN, Valentin JE, Stewart-Akers AM, McCabe GP and Badylak SF: Macrophage phenotype and remodeling outcomes in response to biologic scaffolds with and without a cellular component. Biomaterials 30: 1482-1491, 2009.

112. Reing JE, Brown BN, Daly KA, Freund JM, Gilbert TW, Hsiong SX, Huber A, Kullas KE, Tottey S, Wolf MT and Badylak SF: The effects of processing methods upon mechanical and biologic properties of porcine dermal extracellular matrix scaffolds. Biomaterials 31: 8626-8633, 2010.

113. Elder BD, Kim DH and Athanasiou KA: Developing an articular cartilage decellularization process toward facet joint cartilage replacement. Neurosurgery 66: 722-727, 2010.

114. Woods T and Gratzer PF: Effectiveness of three extraction techniques in the development of a decellularized bone-anterior cruciate ligament-bone graft. Biomaterials 26: 7339-7349, 2005.

115. Nakamura N, Saito K, Kimura T and Kishida A: Recellularization of decellularized cancellous bone scaffolds using low-temperature cell seeding. Tissue Cell 66: 101385, 2020.

116. Hudson TW, Zawko S, Deister C, Lundy S, Hu CY, Lee K and Schmidt CE: Optimized acellular nerve graft is immunologically tolerated and supports regeneration. Tissue Eng 10: 1641-1651, 2004.

117. Conconi MT, De Coppi P, Bellini S, Zara G, Sabatti M, Marzaro M, Zanon GF, Gamba PG, Parnigotto PP and Nussdorfer GG: Homologous muscle acellular matrix seeded with autologous myoblasts as a tissue-engineering approach to abdominal wall-defect repair. Biomaterials 26: 2567-2574, 2005.

118. Poon CJ, Pereira E Cotta MV, Sinha S, Palmer JA, Woods AA, Morrison WA and Abberton KM: Preparation of an adipogenic hydrogel from subcutaneous adipose tissue. Acta Biomater 9: 5609-5620, 2013.

119. Mendibil U, Ruiz-Hernandez R, Retegi-Carrion S, Garcia-Urquia N, Olalde-Graells B and Abarrategi A: Tissue-specific decellularization methods: Rationale and strategies to achieve regenerative compounds. Int J Mol Sci 21: 5447, 2020.

120. Flynn LE: The use of decellularized adipose tissue to provide an inductive microenvironment for the adipogenic differentiation of human adipose-derived stem cells. Biomaterials 31: 4715-4724, 2010.

121. Brown BN, Freund JM, Han L, Rubin JP, Reing JE, Jeffries EM, Wolf MT, Tottey S, Barnes CA, Ratner BD and Badylak SF: Comparison of three methods for the derivation of a biologic scaffold composed of adipose tissue extracellular matrix. Tissue Eng Part C Methods 17: 411-421, 2011.

122. Gilbert TW: Strategies for tissue and organ decellularization. J Cell Biochem 113: 2217-2222, 2012.

123. Petersen TH, Calle EA, Zhao L, Lee EJ, Gui L, Raredon MB, Gavrilov K, Yi T, Zhuang ZW, Breuer C, et al: Tissue-engineered lungs for in vivo implantation. Science 329: 538-541, 2010.

124. Dong X, Wei X, Yi W, Gu C, Kang X, Liu Y, Li Q and Yi D: RGD-modified acellular bovine pericardium as a bioprosthetic scaffold for tissue engineering. J Mater Sci Mater Med 20: 2327-2336, 2009.

125. Hodgson MJ, Knutson CC, Momtahan N and Cook AD: Extracellular matrix from whole porcine heart decellularization for cardiac tissue engineering. Methods Mol Biol 1577: 95-102, 2018.

126. Obata T, Tsuchiya T, Akita S, Kawahara T, Matsumoto K, Miyazaki T, Masumoto H, Kobayashi E, Niklason LE and Nagayasu T: Utilization of natural detergent potassium laurate for decellularization in lung bioengineering. Tissue Eng Part C Methods 25: 459-471, 2019.

127. Shirakigawa $\mathrm{N}$ and Ijima H: Decellularization of liver and organogenesis in rats. Methods Mol Biol 1577: 271-281, 2018.

128. Song JJ, Guyette JP, Gilpin SE, Gonzalez G, Vacanti JP and Ott HC: Regeneration and experimental orthotopic transplantation of a bioengineered kidney. Nat Med 19: 646-651, 2013.

129. Piccoli M, Trevisan C, Maghin E, Franzin C and Pozzobon M: Mouse skeletal muscle decellularization. Methods Mol Biol 1577: 87-93, 2018.

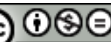

This work is licensed under a Creative Commons Attribution-NonCommercial-NoDerivatives 4.0 International (CC BY-NC-ND 4.0) License. 